\title{
Key Learning Styles of Teaching English to Students from the Asian-Pacific Region
}

\author{
Natalia A. Kovalenko ${ }_{2}^{1 \mathrm{a}}$, Tatiana G. Bekisheva ${ }^{1}$, Gayane A. Gasparyan ${ }^{1}$, Elena V. Yakimenko ${ }^{1}$ \\ ${ }^{1}$ Tomsk polytechnic university, 634050 Lenina str., 30, Tomsk, Russia
}

\begin{abstract}
This article examines key styles of learning English as the second language, particularly for students from Asian-Pacific countries. It deals with the methods of improving their learning skills and abilities. The most traditional and popular ways of learning styles are pointed out. The authors also discuss teaching approaches for matching and interaction of learning styles in different cultures. The authors also discuss teaching approaches to matching and interaction of learning styles in different cultures.
\end{abstract}

\section{Introduction}

A foreign language as the means of communication and knowledge of the world has a special place in the system of modern education because of its social, cognitive and developmental functions [1]. Students of the AsianPacific Region (APR), learning English as a foreign language, have cultural characteristics that complicate the process of communicative foreign language teaching. To achieve the efficiency in learning English modern active methods of teaching are used [2].

The modern process of foreign languages teaching has a communicative orientation. Communicative competence is the main practical purpose of teaching a foreign language. According to methodologists and psychologists it is necessary to develop the ability to communicate in a foreign language, or, in other words, facilitate the acquisition of a foreign language communicative competence.

We think that the problem of formation of foreign language competence in the process of teaching students of the Asian-Pacific region can be considered in two aspects: technological and optimization. The technological aspect is aimed at identifying the tools of teaching, that is, the methods and technologies needed to achieve the best results in the acquisition of knowledge, skills and abilities by students [3].

The optimization aspect is aimed at more efficient and consistent application of existing technologies, depending on the specific features of the educational process. This is particularly relevant in higher educational institutions, where there is a great number of foreign students.

In this article we will discuss both technological and optimization aspects of teaching English to students of the Asian-Pacific region, namely, will describe methods and tools to improve foreign language competence of students.

A typical way of learning students from the AsianPacific region is to provide certain information for remembering or learning. Therefore, many students learning English in their home country have an excellent conceptual understanding of the grammatical structure of the English language, but they cannot speak English and understand it when it is spoken by native speakers. We are, as teachers need to know this feature of learning style, so as not to cause anxiety among the students and help them to increase their level of comfort that will give them the opportunity to participate actively in the learning process, to form a communicative competence and understand spoken English.

Teaching and learning are interrelated - a successful examination outcome requires good materials, good teaching techniques and effective learning on the part of students; but people lean in a variety of ways and have different learning preferences. Knowing the learning style will help to develop coping strategies to compensate for a potential weaknesses and take advantage of strengths.

The term learning styles refers to the concept that individuals differ in regard to what mode of instruction or study is most effective for them. Whilst there are many different models of 'learning styles', they all basically include variations on these three modes:

- Visual learners have a preference for images, they 'think in pictures' and like visual aids that represent ideas such as graphs, charts, diagrams, symbols, etc.;

- Auditory learners learn best through listening to lectures, discussions, tapes, etc.;

- Kinesthetic or tactile learners prefer to learn via experience - moving, touching, and doing things to 'build experience'.

\footnotetext{
a Corresponding author: natalie@,tpu.ru
} 


\section{Visual}

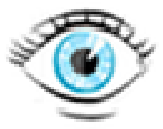

Auditory

Kinesthetic

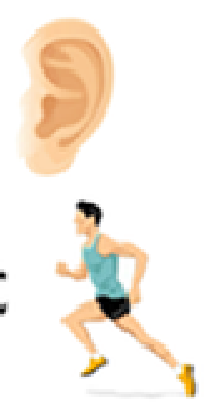

Fig.1. Learning styles

These styles are overlaid with a person's preference for learning is a social or solitary environment and how they absorb and process the information through reflection or other options to create a complex web of possibilities:

There is a plenty of evidence that, if asked, people will express preferences about how they prefer information to be presented to them. There is also plentiful evidence arguing that people differ in the degree to which they have some fairly specific aptitudes for different kinds of thinking and for processing different types of information. Derived from this starting point, the most common hypothesis about the instructional relevance of learning styles is the meshing hypothesis, according to which instruction is best provided in a format that matches the preferences of the learner

However, there is very little evidence to suggest this 'meshing hypothesis' is valid. Whilst we try to include elements of all three styles in our courses, a person's preferred 'learning style' is not a measure of effective instructional design. One of the most widely used models of learning styles is The Index of Learning Styles developed by Dr Richard Felder and Barbara Soloman in the late 1980s, and based on a learning styles model developed by Dr Felder and Linda Silverman [4].

According to this model (which Felder revised in 2002) there are four dimensions of learning styles. Think of these dimensions as a continuum with one learning preference on the far left and the other on the far right.

You can see these in figure 2, below.

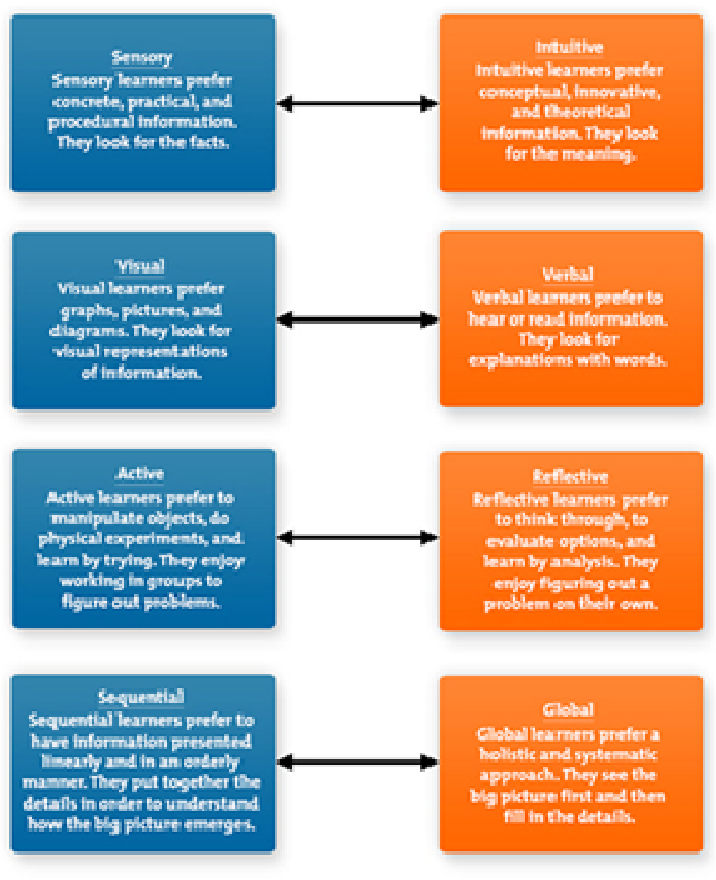

Fig. 2. Index of Learning Styles

Once one knows where her/his preferences lie on each of these dimensions, she/he can begin to stretch beyond those preferences and develop a more balanced approach to learning. Not only will one improve her/his learning effectiveness, one will open oneself up to many different ways of perceiving the world.

Let us consider the traditional learning styles for countries of the Asian-Pacific region. Teaching English as a foreign language in most Asian-Pacific countries is based on the grammar-translation method, with an emphasis on mechanical memory. This traditional approach to the study of a language has influenced the development of a number of typical learning styles, one of which is the introverted (closed) style. Most of the students from the APR perceive knowledge as something that should be transferred by a teacher, but could not be found and studied by the student. Compared with students from other countries, the majority of students from the Asian-Pacific countries are a bit shyer and more reserved during lessons in the classroom. While discussing the various topics they are rarely express their views, do not show their feelings and emotions, and prefer to listen to the opinion of the teacher and classmates. It is the specific feature of the introvert learning style.

It is assumed that the teacher is the only initiative character of the educational process that transfers knowledge in its final form. Therefore, students from Asian-Pacific countries do not like the ambiguity and uncertainty in the learning process.

The most popular style of teaching in APR countries is an analytical style, based on working on textbooks and using a grammar-translation method. At the classes with students of this style, it is common to read new words aloud, repeating after the teacher. The teacher explains the entire text, sentence by sentence, analyzing difficult 
grammatical structures and stylistic devices, and the students listen, write and answer the questions. They usually have no problems when it is necessary to choose an important detail from a large amount of information.

Another type of the learning style is a visual style. Studies have shown that students from Asian-Pacific countries are very good at remembering visual information. They like to read and receive visual support. Students in the audience sit in rows one behind the other, facing the blackboard and lecturers. They reproduce a phrase from the text in a studied language in chorus, or students pronounce in one by one, there are no discussions. Thus, the material is of visual perception (text and board).

The last style of learning, which we would like to consider, is the style of a strict sequence in which students follow the teacher's instructions. They prefer to get language material in the form of combinations of sounds, movements, looks and touches, which can easily be applied in a strict linear sequence. As a part of this learning style, they use a variety of strategies, such as memorization, repetition, analysis, planning and structuring of the material. The tendency of students from Asian-Pacific countries to strict compliance with rules and regulations may be considered as one of the differential characteristics of this style.

Of course, there are exceptions. However, these stereotypical descriptions are based on scientific observations. Studies indicate that, despite the variety of cultures, individuals who are within the same culture are usually inclined to similar models and learning styles and perception compared with other cultures.

Considering the above characteristics of the styles, it can be concluded that for the majority of APR students there are distinctive learning styles. Of the 750 million English-as-a-foreign-language (EFL) speakers, 390.16 million are in China [5]. It is noted that Asia, especially India and China, probably now holds the key to the longterm future of English as a global language. Thus, Chinese speakers of English are an important stakeholder in the linguistic marketplace of global English. It is useful to understand how Chinese learners of English themselves view and experience ELT in China $[6,7]$. You can assume that if English speakers are engaged in teaching English to Asian students, most likely, there will be a confrontation style of teaching and learning. Such differences in the style between students and teachers have a negative effect on student performance. When the learning styles of students agrees with the relevant approaches to learning on the part of the teacher the motivation of students increases, the number of their performances and achievements also increases.

Specificity of a foreign language is that, on the one hand, the mastery of a foreign language speaking activity is a very difficult mental process that requires the students to mobilize their attention, memory, determination, will, and, on the other hand, the process of mastering a foreign language stimulates further knowledge of the world and spiritual values of the peoples of other countries, their psychology and lifestyle [1]. Taking into account the experience of teachers, working with Asian students it is acceptable to use learning approaches, which are classified by the following categories:

1. Diagnostics of learning styles and the development of consciousness of students.

2. Changing of a teaching style to create a style suitable for both teachers and students.

3. Assistance to students behavior change in relation to learning styles.

4. Use of different activities with different groups of students.

Let us consider these approaches in further detail.

\section{Diagnostics of learning styles and the development of consciousness of students}

Effective coordination between the teaching and learning styles can be achieved only when teachers, first of all, know the needs of their students, their capabilities, potential, and their learning style preferences. Although it is not exhaustive, it helps to ensure a constructive feedback on the advantages and disadvantages of different styles.

Before questioning the teacher should conduct a mini-lecture in order to:

- understand what learning styles are in the audience;

- conduct a survey;

- discuss what learning styles are defined and used by students and teachers;

- explain how to calculate the results of the survey;

- convince students of the benefits of identifying their learning styles.

In the course of this lecture, the teacher might ask students to work in pairs and talk about their notes made during the survey. Thus, one can more accurately determine the learning styles. During pair work, the teacher should be prepared to answer any questions. Then the students have to fill in the questionnaire. Finally, students can individually formulate preferences and their individual learning style.

The following step of the teacher is to organize a discussion with the whole group of students, discussing the results of the survey. When these discussions are constructive, students understand their importance and, consequently, improve their self-esteem.

In addition, based on evaluation sheets, the teacher can create subgroups in a group, offering students to join those members of a group whose primary learning styles correspond to their own.

\section{Diagnostics of learning styles and the development of consciousness of students}

In all groups, regardless of what kind the subject is there will be students with different learning styles. An effective tool adapting to these styles of learning for teachers is to change their own learning styles and strategies to ensure different activities of students and meet their needs in a variety of learning styles. Then all 
the students will be able to work with those activities which will meet their learning styles, and they are likely to achieve success in these activities.

In addition, the foreign language teachers should take into account cultural differences in a style. Here is a list of tasks from different learning styles that can be used for students from Asian-Pacific countries.

\subsection{Tasks for the visual learning style:}

1. Reading authentic materials to find new information.

2. Using the handouts.

3. Staging the scenes. Writing stories about any events.

\subsection{Tasks for the analytic learning style:}

1. Ask students to determine whether the sentence makes sense. If it does not make sense, the student changes it so that it would have made sense.

2. Give students a list of related words (such as a list of products, animals, gifts, etc.), and ask them to rank these words according to their personal preferences.

3. Give the students the questions that have two or three alternative answers. The task of students is to choose one of the options in answer to each question.

Learning styles, methods and approaches are selected in such a way that teachers feel comfortable, so the use of global change in styles can make this method inconvenient and not understandable for use. Thus, teachers working with students from the Asian-Pacific region do not need to radically change learning styles [8].

To improve the efficiency of the educational process the teachers should use visual learning tools: photos, drawings, sketches and cartoons to illustrate and reinforce the visual meaning of the word. Show films, videos, and live dramatization to illustrate a lesson topic. They arouse students' interest and positive emotions. Videos offer meaningful information on various topics. Using repetitive training exercises will help to fulfill the basic vocabulary and grammar.

\section{Assistance to students behavior change in relation to learning styles}

The learning style is a consecutive course of actions, which can be changed as a result of training. With the help of special exercises unconscious styles can become conscious learning strategies. An example of such exercises is to avoid gradually the mechanical repetition and use real communication in authentic language situations. Below there are examples of teaching activity which allow Asian students to change their studying behavior and improve ability in mastering the language materials.

- Groups of four or five students are given cards on which the words are written. Everyone describes his/her word in a foreign language to other members without using this word. After this procedure, the group decides to which theme these words relate to and can make up their own story using those words. (For example, words can be objects in the room. In this case, when all the words have been guessed, the group decides which room in the house has been described.)

- Students are placed in pairs or larger groups. Each student has a clean sheet of paper. One of the students or the head of the group has a picture to describe. While one student is describing the picture, the other student is trying to draw it according to the description.

\section{Assistance to students behaviour change in relation to learning styles}

During lessons with students of different learning styles and strategies it is recommended to divide the students into groups according to their learning styles. Usually, students like it, as they get assignments corresponding to their tendency to learn and they feel more comfortable. For example, a group of extroverts need to be able to express their ideas orally. On the other hand, a group consisting of introverts needs some encouragement to share ideas aloud: to write a few sentences at first, and then to talk to one of the group members before participating in a group discussion.

\section{Conclusion}

It should be noted that, regardless of how students are grouped, teachers should deliberately incorporate different learning styles into the daily lesson plan. Do not forget that teacher is the main element responsible for the organization, effectiveness, efficiency and quality of the educational process. Methodically competent organization of the educational process will result in a high knowledge level of students.

\section{Acknowledgment}

The programme was realized and subsided within the framework of the Programme for enhancing Tomsk Polytechnic University's competitiveness. The results presented herein were obtained with the assistance from the Russian Foundation.

\section{References}

1. N.A. Kovalenko, A.Yu. Smirnova, RPTSS, 166, Tomsk, (2014)

2. T.G. Bekisheva, T.G. Gasparyan, G.A Kovalenko, RPTSS, 166, Tomsk,(2014)

3. R. L., Oxford, M. E. Hollaway, \& D. Murillo, ESL/EFL classroom. System, 20/4,(1992)

4. http://www.ncsu.edu/felder-public/ILSpage.html (mode of excess 30.03.2016)

5. B. Norton, Y. Gao, J. of As. Pac. Comm., 18(1), (2008)

6. R. Wei, \& J. Su., Engl. Tod., 28(3), (2012)

7. Na Liu, Chih-Kai Lin \& Terrence G. Wiley Intern. Mul. R. J., (2016)

8. K. Kinsella, J., 6/1, (1996)

9. N. F. Liu, and W. Littlewood, S., 25/3, (1997) 
10. R. L., Oxford, M. E. Hollaway, \& D. Murillo, S., 20/4, (1992)

11. L. Van: A, A. \& Authen., (1996)

12. http://iteslj.org/Techniques/ZhenhuiteachingStyles.html (mode of excess 27.03.2016) 